Revista Iberoamericana, Vol. LXXIX, Núm. 242, Enero-Marzo 2013, 181-194

\title{
VIAJES FANTÁSTICOS: CUENTOS DE [IN]MIGRACIÓN E IMAGINACIÓN DE CLAUDIA HERNÁNDEZ
}

\author{
POR \\ Linda J. CRAFT \\ North Park University
}

La angustia de posguerra por el desplazamiento y la migración caracteriza los cuentos de la salvadoreña Claudia Hernández. Sus dos primeras colecciones, Mediodía de frontera y Otras ciudades, pueden considerarse exploraciones surrealistas de una realidad violenta y deshumanizante-generalmente situadas en una tierra ficticia semejante a su Centroamérica natal-. Si bien estos dos textos tocan a veces la experiencia de irse del país, su tercer libro, Olvida uno, toma lugar completamente en una metrópoli del primer mundo entre varios trabajadores inmigrantes no solamente de El Salvador, sino también de Ecuador, Kazakstán, Checoslovaquia, Bosnia, Bangladesh y otros. Su colección más reciente, La canción del mar, publicada hasta el momento sólo en la revista dominical de La Prensa Gráfica, replantea un motivo favorito, el viaje surreal. Sus personajes regresan, vuelven al hogar o a los orígenes, cerrando un círculo sin haber encontrado fortuna ni sentido afuera. "El hogar", sin embargo, no es necesariamente el lugar de donde salieron: es el hogar, pero al mismo tiempo es un mundo completamente diferente. El hogar es espiritual, el sitio de lo inefable.

De sus cuatro textos, los dos últimos son los que captan más intensamente este movimiento, esta añoranza. En Olvida uno, sus personajes están en el extranjero, aislados, desesperados, humillados, atrapados en puestos serviles y/o absurdos. Hernández se sirve de lo fantástico y lo místico para traducir y a veces trascender lo deshumanizante de la vida del inmigrante indocumentado quien vive en el corazón del capital globalizado. En La canción del mar, sus personajes "regresan” mientras Hernández lleva al lector desde la luz a la oscuridad en busca del espacio para la imaginación, el sueño y el autoconocimiento. El retorno -el viaje interior- es para Hernández la única trascendencia posible. Mientras más se acerca ella a su centro, su estética se hace más intensa y menos material, y sus cuentos más ambiguos y más místicos. 
LA POSGUERRA Y LA CRISIS DEL ESPÍRITU

El situar el corpus literario de Hernández en el contexto de la llamada “posguerra” centroamericana (que siguió a la firma de los acuerdos de paz en El Salvador en 1992) nos ayuda a entender la dirección que toma hacia lo inexpresable y los límites del lenguaje en su viaje interior. Se caracteriza la realidad contemporánea por altos niveles de una violencia que no desapareció con el fin oficial de la lucha armada en 1992. La supuesta transición a la democracia en Centroamérica, según Ileana Rodríguez, se refiere en realidad a los mercados libres, no a las formaciones sociales (“Globalización”). La actual "ficción de democracia”, como la llama ella, consiste en "novelas de la destrucción nacional” que tienen muchos ejemplos de "criminalidad”-las pandillas o maras, maristas, narcotraficantes, terroristas y otros tipos anti-sociales- y los "desechables”, como los pobres, los marginados y los migrantes (“Globalización”). ${ }^{1}$ Werner Mackenbach escribe que un tema general de la literatura hoy día es “el amor en el tiempo de guerra” (con énfasis sobre la palabra "guerra”, digo yo), una guerra que va más allá del conflicto militar para incluir la delincuencia y violencia general de las ciudades, los conflictos domésticos y el maltrato familiar, también las luchas interiores de los individuos (“Cicatrices”). Una guerra ha reemplazado a otra.

La misma Hernández ha identificado una crisis del espíritu con esta etapa: “Creo que somos convulsos porque no tenemos dirección ni orientación” (Entrevista). Se han perdido ideales. La mayoría de los salvadoreños ha crecido conociendo sólo guerra, brutalidad y violencia:

Es nuestra herencia. A nadie que crece viendo este tipo de cosa se le puede pedir luego que sea amoroso, comprensivo, orientado. Mucho del espíritu se ha perdido, no sólo del espíritu que se conoce como espíritu salvadoreño -muy trabajador, buena gente y todo- sino el espíritu por lo general, la humanidad está en una etapa lamentable. La humanidad en general anda muy seca, y entonces no se le puede pedir a la generación ahora que se anden, si todo lo que tienen es puro odio. ¿Has oído aquello de "eres lo que comes”? Nosotros hemos comido un mal y luego no puede esperarse que seamos ni muy humanos ni muy hermosos si lo que hemos consumido es todo odio. (Entrevista)

Aun los que salen (de)formados por esta herencia se encuentran con más experiencias deshumanizantes al otro lado.

La forma que toma esta violencia es sintomática de la presencia o ausencia de sueños utópicos. Las luchas armadas en Centroamérica de los años setenta y ochenta, quizá las

1 En este texto Ileana Rodríguez usa el término "la ficción de la democracia” irónicamente para definir tanto las novelas de construcción nacional de corte idealista como las novelas que narran la destrucción nacional, lo que mayormente ocurre en la posguerra.

Revista Iberoamericana, Vol. LXXIX, Núm. 242,
ISnero-Marzo 2154-4794 (Electrónico) 
últimas boqueadas de los grandes proyectos políticos y sociales de la modernidad, se hicieron bajo la bandera de la liberación nacional. Con la muerte del discurso del estadonación en la era de la globalización ha sobrevenido una realidad fragmentada y caótica (Véase Jeffrey Browitt, citado en Mackenbach, "Realidad”). En los textos literarios que surgen de esta nueva realidad, observa Mackenbach, “[...] no se proponen más mitos, no se cantan canciones heroicas ni se evoca a los mártires. Las grandes propuestas colectivas utópicas han cedido ante una mirada crítica sobre el morir y matar individual" ("Realidad"). Como una nueva forma de la novela testimonial, ${ }^{2}$ dice, estos textos son testigos a la disfunción social general, sobre todo en regiones urbanas: comunicación deformada, aislamiento aumentado y soledad, la imposibilidad de comunicación entre los sexos, la deshumanización del otro, y la violencia sexual y los crímenes "de odio" ("Realidad"). La "nueva novela testimonial”, según Mackenbach, ya no construye identidades individuales: "Las construcciones de identidades en los textos literarios, y también en el testimonio, se están disolviendo, se presentan fragmentadas, llenas de ambigüedades e inseguridades" ("Realidad"). Tales narrativas señalan un cambio a un enfoque más tentativo y menos seguro en cuanto a la naturaleza y función de la literatura.

¿Cuáles son las estrategias narrativas que acompañan los discursos de la posguerra? ¿Es posible que la expresión que da Hernández a lo surreal, lo fantástico y a lo inefable ejemplifique las prácticas textuales del período? ¿Cómo? Primero, Mackenbach apunta la preferencia por lo experimental y lo no-mimético o anti-mimético en oposición a los discursos testimoniales dominantes de los años de guerra, pero nos advierte contra una estética demasiado generalizante; hay todavía una heterogeneidad de formas y estilos literarios en los años recientes ("Después de los pos-ismos"). Mientras Arias ve "un nuevo giro estético hacia el posmodernismo", lo que nació en los ochenta, Magda Zavala explica que una cantidad de novelas de América Central en las últimas décadas del siglo veinte han sido caracterizadas por “una percepción estética muy próxima a las intenciones de la última modernidad literaria, llámese neovanguardista o posmodernismo, por sus prácticas textuales, técnicas y soluciones estilísticas" (citada en Mackenbach ("Después de los pos-ismos”). La experimentación que hace Hernández con el lenguaje y sus límites, con la metáfora y con la fantasía, la magia y lo onírico ${ }^{3}$ es bastante típica

2 La novela testimonial, como emergió de la turbulencia política y social de los setentas y ochentas en América Central, ha sido rigurosamente, quizá demasiado, teorizada. Véase, entre otros, Beverley, Gugelberger, Sklodowska, Zavala, Mackenbach, Zimmerman, Yúdice y Craft. Esta novela está asociada con el período de guerras por la liberación nacional en El Salvador, Nicaragua y Guatemala, y con los discursos idealistas del nacionalismo y modernidad. Mackenbach es el primero, que yo sepa, en usar el término "nueva novela testimonial” para los textos que salen del período posguerra -muy diferentes en carácter, estructura, tono, estilo, tema, etc., a los libros predecesores-. Parece que Mackenbach enfatiza la "función testimonial" -dándoles voz a los sinvoces, documentando injusticias- de tales novelas.

3 No se debe confundir a lo onírico con el realismo mágico.

$$
\begin{aligned}
& \text { Revista Iberoamericana, Vol. LXXIX, Núm. 242, } \\
& \text { ISnero-Marzo 2013, } 181-194
\end{aligned}
$$


de las estrategias narrativas posguerra y también lo es su intensidad. Alexandra Ortiz Wallner ve la relación del proceso literario iniciada en el período de posguerra a la "creación de un nuevo lenguaje y la constitución de un espacio desde el cual se narran las violencias”. Hernández se servirá de un lenguaje neo-vanguardista para narrar no solamente la violencia sino también la búsqueda del sentido en la vida.

Hernández traza estas búsquedas en espacios urbanos mayormente anónimos, ilustrando la descripción que hace Ortiz Wallner del viaje por la ciudad como "una metáfora del viaje existencialista del protagonista, la exploración hacia una profundidad que permanece en la superficie de su ser”. El migrante, frecuentemente un campesino desplazado, se enfrenta con desafíos de proporciones enormes en un ambiente extraño, una ciudad con un idioma que él/ella probablemente no conoce. Tal vez en estas circunstancias la llamada búsqueda por el sentido es un lujo -la misma existencia es una lucha para sobrevivir; no hay tiempo ni energía para más-.

El migrante para Hernández se hace tropo de la condición posmoderna. ${ }^{4}$ A causa del colapso de la nación-estado moderno o quizá el colapso de su ideal -García Canclini en su libro Culturas híbridas nos recuerda que muchas naciones como las de Centroamérica nunca pasaron por la plena modernidad-; los centroamericanos se han ido al Norte en busca de trabajo y en algunos casos asilo político. En una entrevista personal con la autora de este ensayo, la misma Hernández expresa consternación ante las dimensiones del fenómeno: "En Chalatenango dicen que todos los días se van trece. Se imagina una región donde todos los días se van trece. Los de Usulután, del pueblo de mi mamá, cuando uno les pregunta qué va a estudiar, le dice que no, no voy a estudiar, yo me voy en el siguiente. Sólo están criando hijos para que se vayan”. Mackenbach escribe que la migración ha resultado en "un desarraigo": una pérdida de identidad, el nomadismo, el rechazo, y la victimización por los xenófobos en los países anfitriones. La inmigración, para Renato Rosaldo, es un deshacer cultural (81). Si uno se fija en los titulares de los periódicos se dará cuenta de las consecuencias del desplazamiento en los inmigrantes. Su situación es aún más complicada por la facilidad de comunicaciones por el teléfono y el internet, el cruce relativamente fácil de la frontera (con la excepción de los viajes horrorosos por los desiertos del suroeste de Estados Unidos), el fluir del capital internacional y los envíos de remesas a América Latina. Los antiguos modelos de asimilación al nuevo país ya no sirven, puesto que muchos migrantes pueden mantener un pie en cada lado; muchos aun quieren regresar a su país algún día. Rosado nota la ironía de la situación de los indocumentados: "They simultaneously accede to and resist their cultural homogenization. Even as they move toward co-optation, they prove

4 Se dice que por lo menos una quinta parte de los salvadoreños viven fuera de su país, la mayoría en los Estados Unidos (Los Ángeles es la segunda ciudad salvadoreña del mundo después de San Salvador), pero muchos se mudan a Canadá, Australia o Europa.

$\begin{array}{llllll}\text { Revista Iberoamericana, Vol. LXXIX, Núm. 242, } & \text { Enero-Marzo 2013, } & \text { 181-194 } \\ \text { ISSN 0034-9631 (Impreso) }\end{array}$ 
unassimilable” (84). Sus lealtades parecen sospechosas (aunque se puede preguntar qué lealtad dado el hecho de que los indocumentados no han sido bienvenidos oficialmente de todos modos). Por esta razón y otras, los indocumentados e incluso los que sí tienen documentos se enfrentan al racismo, discriminación y explotación en sus países de adopción. ${ }^{5}$

\section{OLVIDA UNO}

Los inmigrantes de todas partes del mundo pueblan la ciudad en Olvida uno. Los cuentos comparten espacio en un mundo de experiencias literalmente ultramundanas. Los universos infinitos penetran éste; los animales de toda clase atormentan la existencia; las visiones aparecen en los espejos; un baño privado promete una "espesura cósmica” (29); una joven se mete una estrella en el bolsillo para crear un nuevo universo cuando sabe que el viejo fue violado. Las fuerzas del olvido y la nostalgia ("los lobos”) se encuentran para aumentar la tensión narrativa. Los personajes están encerrados en el aislamiento, la servidumbre humillante, una idiotez chistosa y/o la desesperanza. Hernández usa lo fantástico para representar la inhumanidad y lo absurdo de la vida de un trabajador inmigrante sin documentos que vive en el Norte.

El personaje de Lourdes en el cuento central, "La han despedido de nuevo", es salvadoreña, y su historia errática como empleada es típica de los vaivenes de la fortuna de muchos trabajadores latinoamericanos. Sin embargo, Hernández universaliza la experiencia para incluir a la gente de orígenes humildes de África, el Medio Oriente, la Europa oriental, Rusia, Kazakhstan, Grecia y los países escandinavos: todos los que se encuentran en circunstancias semejantes. Aunque ocupan viviendas atestadas de seres humanos en la metrópoli, hay poca comunicación. La mayoría permanece anónima e invisible. Por ejemplo, el polaco operador del ascensor en el cuento "Graciela insiste en que vine a eso de las diez” es muy culto y erudito porque en su vida previa fue joyero; ahora, no obstante, languidece por la actriz que transporta de arriba a abajo. Qué pérdida, piensa el narrador: “Aunque a él parecía no molestarle, era una lástima que tuviera que estar empleando sus dedos de joyero para oprimir botones” (34).

Hay más gente perdida. María de Bosnia de "Le gusta espresso" es prescindible y en la mente de su antiguo compañero sueco, Nelson, está destinada “para el olvido” (133). Está enferma, quizá paranoica y obsesionada por el olor de Sarajevo en la primavera:

5 Tal vez sea demasiado temprano decir si los modelos tradicionales de asimilación servirán ya que tantos inmigrantes contemporáneos son de la "primera generación”. Si acaban quedándose en Estados Unidos, sus niños probablemente aprenderán inglés y lograrán ascenso social como en las generaciones previas. Y el sentimiento anti-inmigrante no es nada nuevo en Estados Unidos. Pero dadas las conexiones fáciles y baratas con sus países de origen, es posible que haya otro resultado como una asimilación incompleta o parcial.

\footnotetext{
$\begin{array}{llllll}\text { Revista Iberoamericana, Vol. LXXIX, Núm. 242, } & \text { Enero-Marzo 2013, } & \text { 181-194 } \\ \text { ISSN 2154-4794 (Electrónico) }\end{array}$
} 
“Sarajevo huele a carbón” (135), las cenizas de las casas y los cuerpos incinerados en la guerra. En otro cuento, "Anila había ido a almorzar con la albanesa del segundo piso", un bangladesí solitario trata sin éxito de buscar una manera de iniciar una conversación con los demás, mientras un colombiano, quien había vivido en la selva, le narra a una prostituta sus recuerdos tristes de haber visto "pasar por el río un sinfín de cuerpos de gente que había muerto sola” (140). Esta ciudad es un lugar en que tanto la prostituta como el cliente están "de paso", y el amor es tan transitorio, según el narrador de "Déjà vu tal vez", que a menudo uno de los clientes "con los que me voy me llama por el nombre de otra mujer cuando estamos en la cama” (127). La zona urbana en que viven es impersonal, amorfa, como cualquier otra, no muy accesible ni acogedora. Si alguien decide mudarse, "[t]ampoco padecería por tener una mujer menos" (147). Nadie la echará de menos; la ciudad se olvida rápido.

Es más, el olvido es un tema que une todos los cuentos, y un término usado en cada uno, aunque en distintos contextos. Hernández sugiere que la nostalgia, un sentimiento común cuando uno está lejos de su tierra en circunstancias difíciles, puede ser debilitante. Dice que "Olvida uno" puede ser el título para cualquiera de los cuentos de la colección (16). Un recién llegado, por ejemplo, quien todavía no ha "adoptado la costumbre local de estar solo" (11), está contento de encontrar un apartamento que no se puede cerrar con llave porque, como dice, "soy de los que olvidan siempre las llaves" (10). No obstante, alcanza los límites de su paciencia y sociabilidad a medida que desconocido tras desconocido entra y sale de su cuarto como si tal cosa. La actriz Graciela, quien tiene "una muy mala memoria" (33), se olvida de registrar los detalles de alguien que sigue llamándola por teléfono para hostigarla. Otros transeúntes se consuelan en los brazos de las prostitutas cuyas "acogidas los hacen olvidar que están en esta ciudad" (139).

Hay una metáfora particularmente graciosa para el libro en el cuento de Lourdes. Uno de sus varios trabajos es cuidar a un anciano con enfermedad de Alzheimer, Albert, el único blanco que la trata "como a un familiar" y no como a una sirvienta. La esposa de Albert, sin embargo, mantiene a Lourdes a distancia pero irónicamente quiere que le enseñe español "para que consiga tranquilizarlo como yo lo hago cuando le dan los arranques de furia, que lo llamo Albertico y le pido que sea bueno hasta que se calma por completo y me pide que lo lleve a tomar una siesta pequeña” (110). El episodio sugiere que el olvido en realidad pudiera adelantar la adaptabilidad y aceptación.

El trabajo que hacen Lourdes y los otros inmigrantes, observa Hernández, es el más bajo en prestigio y pago. En los cuentos conocemos a los personajes que limpian casas, cuidan a los ancianos, se ocupan del guardarropa en el Capuccino Café, sudan en las fábricas, salones de belleza, mueblerías, panaderías, hoteles y charcuterías. "La han despedido de nuevo" es un título apropiado para el cuento de Lourdes: comienza gramaticalmente con un objeto directo, femenino en este caso, emblemático del estatus objetivado de muchos migrantes. En efecto, se puede leer Olvida uno como una guía

\footnotetext{
Revista Iberoamericana, Vol. LXXIX, Núm. 242, Enero-Marzo 2013, $181-194$
ISSN 2154-4794 (Electrónico)
} 
para sobrevivir la emigración. Una señora salvadoreña que sí tiene documentos como residente legal recuerda a los recién llegados, incluida Lourdes, que "[a]cá no es como allá” (47). La señora aconseja que no confraternice con los clientes ni con otros empleados agregando algunos consejos adicionales como cuidado con los hombres, no sonrías demasiado, ten cuidado con los negros en Coney Island, toma clases de inglés, llega a tiempo, ponte bonita, haz tiempo para ti misma, cásate con un gringo para ser legal, pero hasta ese momento, sal con los otros y “sácale todo lo que puedas” (57). Ella explica la jerarquía social y las relaciones delicadas entre las razas, los puertorriqueños se consideran superiores a otros latinos porque son ciudadanos, pero "los puertorriqueños tienen mala fama. No les gusta trabajar” (61). Y señala los trabajos que hay que evitar: "Las fábricas son horribles, mi amor. Recién venida, yo trabajé en una. De abrigos era. No quiero ni acordarme. Ganaba muy mal y todo el tiempo estaba pensando en si llegaba la Migración...” (54-55).

Lo que hace particularmente convincentes los cuentos de Hernández es el punto donde sus migrantes se encuentran con lo fantástico. Hay elementos surrealistas en su ficción previa, una cualidad soñadora, aun alucinante, que sigue en la colección presente. En los libros iniciales y también en Olvida uno, sin embargo, Hernández escribe en prosa con total naturalidad, en un tono a veces un tanto inexpresivo en su narración de "los lobos", por ejemplo -lobos que rondan a los recién llegados y les echan la nostalgia a la cara-; o de "las voces" que un joven trae a su apartamento de la calle "pegadas al abrigo”, aterrorizando a la novia de su compañero de cuarto. De vez en cuando Hernández incorpora el fluir de la conciencia, el estilo indirecto libre y los cambios de perspectiva inesperados para realizar lo onírico y lo fantástico.

Se puede leer Olvida uno como un viaje fantástico o un viaje adentro de la fantasía. El crítico George Aichele, relacionando lo fantástico con lo posmoderno, escribeque el cuento fantástico desconstruye la necesidad de interpretar el texto: "Like madness, postmodern fantasy disrupts and transgresses conventional, 'sane' boundaries between things and words, signifieds and signifiers, present reality and always-fictitious representation. For postmodernism, fantasy and madness are one; they are both non-sense” (14). La narrativa trata de manejar y expresar el caos de desplazamiento y migración, expresándolo, manipulando y contestándole, a veces imitándolo. La experiencia contemporánea, explica George Olsen, "is one perceived as continually beyond belief, one of a culture that perceives itself as undergoing physical and metaphysical erasure” (citado en Aichele 15). Aichele acaba diciendo que "the fantasy comes true", o sea, se desbarata la realización de la utopía. Citando a Olsen, escribe: “Just beyond a postmodern narrative, fantasy would find its pure state, and at that vanishing point it would completely cease to mean anything” (Aichele 1). Los significantes ya no significan nada. Las crisis de migración contemporánea implica no solamente la pérdida del hogar y de la identidad, sino también la pérdida del sentido. En el texto de Hernández los personajes se mueven inútil e impotentemente en un mundo en que son deshumanizados y borrados.

Revista Iberoamericana, Vol. LXXIX, Núm. 242,
ISSN 0034-9631 (Impreso) 
Los animales, como intrusiones de lo fantástico, se destacan en los cuentos de Hernández. Explica que los incluye en Olvida uno porque “[...] los animales son como la nostalgia, que tratan de llevársela [a Lourdes], y todo el mundo le dice cuídate de la nostalgia. Y no, cuando empieces a sentir eso, al dejarte hacer tal cosa o hacer tal otra que no te gane la nostalgia, si haces que la nostalgia no te gane, vas a tener una buena vida” (16). En "La han despedido de nuevo", “el lobo de piedra” declara que la joven e inexperta Lourdes es víctima de la explotación por sus patrones -judíos ortodoxos- quienes le pagan mal y la someten a condiciones de trabajo difíciles. Este lobo le ruega a Lourdes que lo siga a Nuevo México. Así lo hace. Es casi imposible resistir a los "animales que rondan las calles en busca de muchachas" (95). Ella vacila, eventualmente regresando con el chino con quien ha vivido como concubina -"No me gustaba el chinito, pero me gustaba menos tener que comer mierda" (55)- y quien quiere que ella tenga su bebé. Mientras tanto, ella sale con un policía irlandés; el librero del barrio le aconseja que tenga un aborto; y el lobo sigue llamándola. Otros animales empiezan a acosarla: "los gatos de sombras [...] a veces me rondan" o "el torogoz de agua" y "el perrito de cristal”, todos "pueden resultar muy peligrosos por el asunto ese de que se llevan a las chicas lejos de la ciudad" (108). A veces no es claro quiénes son las verdaderas bestias: los hombres explotadores (y mujeres también) en su mundo o los animales peligrosos que la atraen.

El narrador admite las consecuencias de siempre estar en las garras de otros: "A su edad, las mujeres saben lo que hacen y lo que les conviene. Pero no es su caso” (99). El implacable Sr. Orestes seduce a la Lourdes en otra incursión a lo fantástico. Orestes, "el hombre sin cuerpo", favorece a las mujeres presas de animales y por eso persigue a Lourdes. Parece que él quiere que ella le dé a luz a él: "[S]e adueña de las mujeres que aceptan traerlo al mundo". Les asegura que las va a entregar a casa "tras parirlo, pero es una mentira” (99), dice el narrador. Lourdes cae en la trampa de este espíritu profano y acepta "la idea absurda de dar a luz un hijo que es su mismo padre" (117). Hernández explica que la presencia del señor Orestes "responde a un planteamiento de fondo del libro: que las formas primitivas de conocimiento (llamémoslas mágicas) siguen siendo posibles en nuestro tiempo, incluso en las grandes ciudades y los espacios de economía y tecnología avanzada” (Entrevista). ¿Por qué acepta Lourdes ir de buena gana? Porque es una fuerza difícil de resistir: "La esfera mágica es así” (Entrevista). Al fin y al cabo, el narrador -alguien que ha mantenido contacto con Lourdes y que la ha seguido en su migración- trata en vano de rescatarla explicándole lo absurdo de parir al hijo que es su propio padre. Entonces "la entregué a los animales que libran a las mujeres de la noche perpetua de la ciudad y las llevan de regreso a casa” (117-18).

La estructura circular de la historia de Lourdes -su llegada, los primeros días de un trabajo irregular, sus relaciones sociales en las zonas urbanas marginadas y su salida inminente para su hogar- es análoga a la trayectoria narrativa de toda la colección de cuentos en Olvida uno. Huyendo de la miseria económica, el caos social y la desintegración

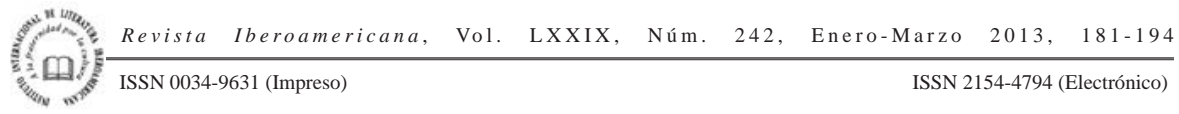


política en sus países natales, los personajes de Hernández encuentran solamente más marginalización en el Norte. Además, para sobrevivir deben "olvidar” su pasado, sus raíces, su identidad en lo que Rosado llama un "cultural stripping away” o, como la misma Hernández lo llamaría, un “Alzheimer’s cultural” (Entrevista). A la vida le falta sentido. Lourdes y muchos otros tendrán que irse para evitar ser borrados.

\section{LA CANCIÓN DEL MAR}

Los cuentos de Hernández sugieren la aparición, tal vez la necesidad, de lo irracional o lo fantástico -animales que rondan, espíritus y fuerzas mágicas de una espiritualidad profundamente arraigada en el pasado- aun en una metrópoli posmoderna. El viaje de sus personajes resulta ser no solamente económico sino también espiritual. Este tema, que está presente en Olvida uno, será central a la colección de cuentos más reciente de Hernández, La canción del mar. Aquí, la autora sigue a los migrantes en su "vuelta”, su viaje interior, un movimiento lírico hacia el auto-conocimiento y la intuición: "[E]s acerca de lo que se aprende una vez que alguien se ha movido. De alguna manera, el movimiento provee de ojos nuevos”, explica Hernández (“Cuando”). A esta colección Hernández la llama “un microlibro”, “una chiquitinada” (Entrevista), piezas breves pero intensas organizadas más por la idea que por la trama. Los cuentos son de dos hasta ocho párrafos. Para Hernández, el cuento es un género ideal para sus propósitos ya que “mide la cara mágica del mundo” (“Cuando”).

El cuento que abre la colección, "La noche”, fija el tono. Su estructura es circularempezamos y terminamos con la noche: "La noche es con nosotros silencio y un parpadear de estrellas”; y finalmente, "A nosotros la noche nos concede seguir siendo nosotros mismos día con día por el resto de nuestros días” (Canción 3). Noche, día; opuestos, contradicciones que parecen o eliminarse el uno al otro o coexistir imposiblemente. Una voz de la noche empuja al viajero a seguir “el camino de vuelta a su lugar” (Canción 3). Al fondo del sendero se entra "en un claro que no está hecho para ser anclado con los pies [... S Se deja el cuerpo a la sombra de un árbol” para continuar a "su antigua morada” (Canción 3), una experiencia incorpórea, a medida que se acerca a la morada espiritual.

La crítica Sharon Keefe Ugalde observa un semejante deseo por la restauración o la reintegración espiritual de parte de muchas poetas que escribían en España a finales del siglo veinte, lo que nos ayuda a entender el contexto general de Hernández: "Se podría pensar en nuestro mundo global de ahora como el no-lugar, el no-centro, la nofijación. El espacio anónimo trastornado lleva a la fragmentación de la subjetividad, un estado doloroso de desorientación, y al anhelo de la reintegración en espacios que tengan significación”. Ugalde encuentra esperanza en los números crecientes de mujeres escritoras que están publicando ahora. Hernández no tiene tanta esperanza, tampoco le interesan mucho las actividades de las mujeres escritoras como una declaración del

\footnotetext{
Revista Iberoamericana, Vol. LXXIX, Núm. 242,
ISSN 0034-9631 (Impreso)
} 
“progreso”. Quizá su enfoque sea más fundamental. Lo que sí comparte con Ugalde es el "anhelo de la reintegración”, el deseo por la identidad, el lugar, y el sentido que sus personajes buscan en sus peregrinaciones espirituales. Ésta es la reacción de Hernández a las corrientes deshumanizantes de la globalización, su respuesta a los altos niveles de violencia.

El poder de la magia abre un espacio que se resiste a la deshumanización. Los niños en La canción del mar habitan un mundo mágico y natural más cómodamente que los adultos. Un niño le habla a una tórtola por siete horas antes de que dos “lóbregos pájaros” se la lleven devorándola antes sus ojos (Canción 6). Otro niño escucha "maravillado” los cuentos de un viejo marinero en los que éste le narra episodios de su niñez cuando su “corazón era uno” con el de las acacias. Al oír de su unión con los árboles y las sombras, la madre del chico, quien piensa que su hijo es víctima de una imaginación hiperactiva, manda que se corten las acacias: "Pero perdió la sonrisa cuando, al llegar la tarde, su hijo se paseó por el camino de siempre y las criaturas a las que había tratado de espantar acudieron a su llamado y se posaron sobre las ramas de unos invisibles árboles que ella no podría derribar” (Canción 7). Y en un tercer cuento de magia, unas hermanas jóvenes escuchan una voz “dulce” y "severa” en el jardín “que provocaba que las cortinas de la habitación se elevaran del suave modo en que lo hacen cuando el viento de final del invierno entra a casa” (Canción 8). La voz les enseña "hermosas canciones que no podían ser entonadas por voces humanas. Su sonido estremecía siempre nuestros corazones y dificultaba nuestra respiración” (Canción 8). Pero empiezan a temerlo porque sedujo a un tío que huyó para nunca volver. Con el tiempo la voz desaparece: "se convirtió primero en un murmullo lejano; luego, en silencio y, después en vacío” (Canción 8). En una frase paralela lírica, las hermanas se dan cuenta demasiado tarde de lo que han perdido: "Disfrutamos las horas y el silencio hasta que, con el paso del tiempo, el vacío se nos volvió primero inquietante, luego lamentable y después angustiante” (Canción 8). La oportunidad de escuchar las voces mágicas con el corazón se ha ido para siempre a los que se niegan a aceptarlas. La melodía tierna se convierte en "la terrible canción” de su nostalgia.

Las experiencias de David en "Nostalgia de Anna Braun” recuerdan las transformaciones de la "madurez" que hemos visto en los otros cuentos. Ahora hombre, David regresa a la ciudad -“esa ciudad” sin nombre que habitó cuando niño- para visitar la sastrería donde jugaba mientras su madre trabajaba. Aunque el joven David mostraba promesa como artista en ciernes y le encantaba dibujar retratos, su madre trataba de disuadirle de este talento, enviándolo en cambio a estudiar contabilidad. Pero ahora, muchos años después, sintiendo un vacío y una añoranza inexplicables, David le revela al sastre que ha venido en busca de “Anna Braun”, a quien extrañaba más que nada: “Anna Braun [era] la diminuta figura de porcelana de una mujer, sin rostro, que el señor Fridman mantenía de bruces en la gaveta del escritorio donde guardaba los

\footnotetext{
Revista Iberoamericana, Vol. LXXIX, Núm. 242, Enero-Marzo 2013, $181-194$
ISSN 2154-4794 (Electrónico)
} 
lápices y que David, quien la había bautizado con ese nombre, sacaba para jugar cada vez que dibujaba. Entonces decidió preguntar por la que le daba nombre a su nostalgia ...” (Canción 4-5). El señor Fridman, tristemente dándose cuenta de que "la propietaria de la figura estaba enviando por ella”, se la deja a David, pero no antes de avisarle de "las incontables noches sin sueño ni sosiego que le esperaban... [porque] no era un juguete o un caprichoso adorno, sino la representación de la dueña de las palabras que no pueden ser dichas, una incorpórea mujer" que hace mucho tiempo visitaba al sastre cuando la madre de David se ausentaba (Canción 4-5). (En aquellos días, David, al otro lado de la cortina, podía observar sólo los “inmaculados pies desnudos” de la mujer, los que parecían flotar ante sus ojos). Esta "emperatriz del mundo" muda y sin cara ahora acompañará a David, "frente al rostro que en adelante se revelaría para él” (Canción 4-5). El sastre ya no podrá ver ni recordarla. La mirada de la figura es intransferible al antiguo dueño. "Es lo inefable”, explica Hernández, "[p]asa que ese rostro que no podemos ver está de alguna manera en todos los rostros" (Entrevista). De vuelta en su hotel, David escucha la "iridiscente voz de una forma femenina que 'conocerás la noche’ le decía...” (Canción 4-5). Ella lo lleva tomado de la mano hacia la noche. El cuento sugiere unas cuantas interpretaciones: la imaginación del niño es latente en el adulto; la nostalgia tira con más fuerza al paso del tiempo; la emperatriz del mundo, Anna Braun, es una posesión codiciada que pasará del viejo al joven; y esta posesión mágica irónicamente tomará posesión de su dueño a quien no concederá ni descanso ni sueño en la larga noche. ¿ No se podrá satisfacer jamás la añoranza?

"El rostro", como el ausente de Anna Braun, es un tropo recurrente en La canción del mar, a veces refiriéndose a un concepto místico del tiempo y la posibilidad de ver por el tiempo a la eternidad. Hernández introduce el cuento "Luz de enero" con un epígrafe breve escrito por un colega salvadoreño, Jorge Galán: "Y el destino que ando transita todos los destinos, porque, de alguna forma, un tiempo es todos los tiempos y un segundo es solo otro rostro para mirar la eternidad” (Canción 8). La historia empieza con una referencia a la hora del reloj, la hora histórica: "A la luz de las tres de la tarde, una mujer de cabello ensombrecido" (Canción 8) camina hacia su casa, pasando una esquina donde "el viento que desciende" (Canción 8) la ha estado esperando por tres años. Aunque ella se encuentra en "otras latitudes” en "ese país”, entiende que los niños que ve en este momento "no son solo ellos mismos, sino también los de los años en que tenía ella una mariposa azul en el pecho y caminaba por esa calle de la mano de un abuelo que sembraba a su paso flores amarillas y ceniza” (Canción 8); estos niños son también el hombre que fue su amante, "con el que pasaba las noches en el tiempo en que no lo conocía ni la conocía él” (Canción 8). El tiempo es fluido, sin fronteras. Esta mujer ve su pasado en el presente y vice versa. Las frases de Hernández corren en una serie rítmica de metáforas que se alternan la una con la otra: "Era él esa calle ... Era ella pasando ... Era el viento que desciende ... Era ella negándose ... Era el viento

\footnotetext{
Revista Iberoamericana, Vol. LXXIX, Núm. 242,
ISSN 0034-9631 (Impreso)
} 
que desciende ... Era ella mirando ... Era ella entendiendo ... dejando el país del otoño y volviendo este día” (Canción 8) -saliendo y volviendo, terminando donde empezó, con el entendimiento de que el tiempo son todos los tiempos y un segundo es solo otro rostro para ver la eternidad-. Nos recuerda el Aleph de Borges, "uno de los puntos del espacio que contienen todos los puntos [...] el lugar donde están, sin confundirse, todos los lugares del orbe, vistos desde todos los ángulos” (64). Como el personaje de Borges, la mujer de Hernández está contemplando el infinito, la eternidad.

El carácter soñador, mágico y circular de la prosa y visión de Hernández brota de una ética vanguardista en La canción del mar. Una mujer dormida "ve" a un intruso, un hombre de una ciudad lejana del sureste que habitaba alguna vez, dentro de y fuera de sus sueños mientras las ventanas personificadas de su cuarto "parpadean nerviosas" y una "maliciosa bruma" comienza a acosarla ("Elegía de las ventanas", Canción 9). El lamento de las ventanas oscurece la ciudad al fin del cuento porque ésta, su hija, “se hará una con el sueño’ y encontrará “la energía que le permitirá ver lo que está y lo que no está y oír lo que se dice y lo que se pronuncia jamás”. Unas yuxtaposiciones insólitas de las metáforas transportan al lector a otro mundo y a otro tiempo en que otra vez todo y nada es visible y audible. La lógica deja de funcionar, y el lenguaje opera en otro nivel. Tal vez ya no sirva para nada el lenguaje.

Se intensifica lo efímero en el último cuento. En "El bar de la calle Hudson”, la protagonista Eva Stroud y su amiga regresan a su ciudad natal donde Eva entra al bar del título "en la oscura ausencia de cosas visibles". Es de noche. Es un bar de sorpresas y contradicciones en que el tiempo está congelado, invadido por lo surreal. Ningún cliente comparte la misma experiencia: algunos hombres entran y se encuentran "consigo mismos"; otros descubren el olor del "tiempo detenido"; otros pocos disfrutan bebidas y salen sin incidente mientras a otro lo devora "el hocico de una bestia"; y el último encuentra el mar y una canción acerca de "la luz y la oscuridad que lo extasió de tal manera que olvidó la lengua de los hombres y habló solo en adelante en el idioma de la inmensidad" (Canción 9). Una luminosidad cubre todo, pero luego la protagonista "se absorbió a sí misma y a todo lo que la rodeaba y dijo en una lengua no audible que era la nada también” (Canción 9). Eva se va del bar, caminando "como una sombra entre las sombras" (Canción 9). Su última sorpresa viene en casa cuando su amiga le pregunta si viene del bar de la calle Hudson. Claro que sí, contesta Eva, "porque sabía que no existía tal bar puesto que no había una calle Hudson en esa ciudad”. El bar de Eva en la Hudson Street es "el no-lugar, el no-centro, la no-fijación” de Ugalde, ya descrito. Es interesante que el único lugar con nombre en esta colección no exista. Todo -lugar y personaje- se convierte en la nada.

Sin lugar, sin centro, sin parada, el nómada posmoderno no tiene otra salida que un viaje metafórico a la tierra de los sueños. Habiendo dejado atrás su patria devastada por la violencia de la posguerra, los migrantes desarraigados de Olvida uno descubren

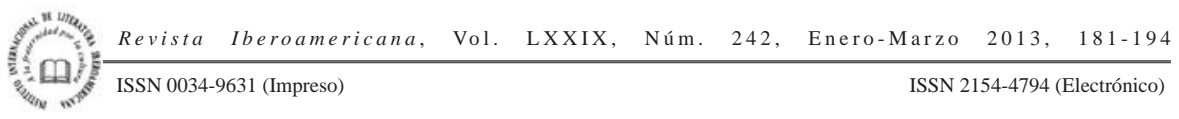


su propia invisibilidad en territorio ajeno, desangrándose en los empleos más humildes y más humillantes. Para sobrevivir, se retiran irónicamente hacia adentro en La canción del mar, para contemplar y soñar en la noche, lo que les puede resultar amenazante. Pero al mismo tiempo así se provee un espacio para la imaginación. No se puede regresar al punto de origen geográfico sino a un mejor auto-conocimiento. Su morada ahora es el corazón y la imaginación, un refugio para los recuerdos y la nostalgia. Por eso, le sirve a Hernández una prosa poetizada que transforma al cuento en que se presenta otra realidad. Con sus imágenes y lenguaje que destilan lo fantástico, lo místico y lo mágico, Claudia Hernández logra rescatar el espíritu en un momento histórico profundamente anti-espiritual.

\section{BiBLIOGRAFÍA}

Aichele, George. "Postmodern Fantasy, Ideology, and the Uncanny”. Para*doxa 3/3-4 (1997): 498-514.

Borges, Jorge Luis. “El aleph”. El Aleph. Madrid: Alianza Editores, 1995. 60-69. <http:// www.textos enlinea.com.ar/borges/El\%20aleph.pdf>. 9 sept. 2009.

García Canclini, Néstor. Culturas híbridas. Estrategias para entrar y salir de la modernidad. México: Grijalbo, 1990.

Hernández, Claudia. Carta personal. 28 agosto 2007.

“Cuando busco la literatura busco a la persona”. Entrevista por Ruth Gregori. El

Faro. 1 dic. 2006. <http://poesimistas.blogcindario.com/2008/08/01129-cuandobusco-la-literatura-busco-a-la-persona.html>. 12 mayo 2009.

Entrevista personal. Junio 2006/agosto 2008. San Salvador.

La canción del mar. Revista Dominical. La Prensa Gráfica (10 junio 2007): 2-9. Mediodía de frontera. San Salvador: Dirección de Publicaciones e Impresos, 2002. Olvida uno. San Salvador: Índole, 2006.

Otras ciudades. San Salvador: Alkimia, 2001.

Mackenbach, Werner. “Cicatrices: Un retrato del cuento centroamericano”. La Prensa Literaria. 8 mayo 2004. <http://archivo.laprensa.com.ni/archivo/2004/mayo/08/ literaria/cuento/>. 27 dic. 2005.

“Después de los pos-ismos: ¿desde qué categorías pensamos las literaturas centroamericanas contemporáneas?” Istmo: Revista virtual de estudios literarios y culturales centroamericanos 4 (2004). <http://collaborations.denison.edu/istmo/ n08/articulos/pos_ismos.html>. 17 mayo 2009.

"Realidad y ficción en el testimonio centroamericano”. Istmo: Revista virtual de estudios literarios y culturales centroamericanos 2 (2001). <http://collaborations. denison.edu/istmo/n02/articulos/realidad.html>. 20 junio 2007.

Revista Iberoamericana, Vol. LXXIX, Núm. 242,
ISSN 0034-9631 (Impreso) 
Ortiz Wallner, Alexandra. "Transiciones democráticas/transiciones literarias: Sobre la novela centroamericana de posguerra”. Istmo: Revista virtual de estudios literarios y culturales centroamericanos 4 (2004). <http://collaborations.denison.edu/istmo/ n04/articulos/transiciones.html>. 17 mayo 2009.

Rodríguez, Ileana. "Globalización y gobernabilidad: Desmovilización del gestor social nacional en Centroamérica”. Istmo: Revista virtual de estudios literarios y culturales centroamericanos 13 (2006). <http://collaborations.denison.edu/istmo/ n13/articulos/globalizacion.html>. 20 junio 2007.

"Perspectivas eco-críticas latinoamericanas: Conocimientos transpuestos recuperados”. LASA Forum XL/1 (2009): 30-33.

Rosaldo, Renato. "Place and Voice in Anthropological Theory”. Cultural Anthropology 3/1 (1988): 77-87.

Ugalde, Sharon Keefe. "Redefiniendo los límites: La representación del espacio en la poesía española escrita por mujeres (1950-2000)”. Texto recogido en las Actas del VIII Encuentro Internacional de Mujeres Poetas, publicado por Diputación Foral de Alava en 2006. <http://olerki-poesia1.blogcindario.com/2007/05/00273la-representacion-del-espacio-en-la-poesia-escrita-por-mujeres-por-sharon-keefeugalde.html>. 19 mayo 2009.

Revista Iberoamericana, Vol. LXXIX, Núm. 242, Enero-Marzo 2013, $181-194$
ISSN 2154-4794 (Electrónico) 